\title{
Association Between Polymorphism at IGF-1 rs35767 Gene Locus and Long-term Decline in Renal Function: A Retrospective, Cross-sectional, Longitudinal Cohort Study
}

Kosuke Honda ( $\sim$ hondajam@jikei.ac.jp )

The Jikei University School of Medicine

\section{Satoru Kuriyama}

The Jikei University School of Medicine

Kimiyoshi Ichida

Tokyo University of Pharmacy and Life Sciences

\section{Tomoko Nakano}

Health Management Center of the Tokyo Regional Taxation Bureau Clinic, Tokyo

\section{Naoki Sugano}

The Jikei University School of Medicine

\section{Takashi Yokoo}

The Jikei University School of Medicine

\section{Research Article}

Keywords: IGF-1, Gene polymorphism, Blood pressure, Glomerular filtration rate

Posted Date: January 19th, 2021

DOI: https://doi.org/10.21203/rs.3.rs-146566/v1

License: (c) (i) This work is licensed under a Creative Commons Attribution 4.0 International License.

Read Full License 


\section{Abstract}

Background: Insulin-like growth factor-1 (IGF-1) acts on glucose and protein metabolism and human growth and also influences blood pressure and renal function. This study investigated whether the singlenucleotide polymorphism of IGF-1, rs35767, plays a role in metabolic syndrome indicators, including blood pressure, glucose metabolism, uric acid levels, and renal function.

Methods: In this retrospective, cross-sectional, longitudinal cohort study, blood samples from 2601 Japanese individuals were collected and used for genotyping for variant rs35767: T > C in the IGF-1 upstream promoter. Data were analyzed to identify associations between IGF-1 genotypes and patient biochemical parameters, including the components of metabolic syndrome and the long-term change in renal function.

Results: The cohort rs35767 genotypes included 1124 CC carriers (43.2\%), 1180 TC carriers (45.4 \%), and 297 TT carriers (11.4\%). Multiple regression analysis revealed no association between IGF-1 genotype and systolic blood pressure, glycated hemoglobin level, and serum uric acid level. However, in females, diastolic blood pressure and mean blood pressure were negatively correlated with the TT genotype. In a cross-sectional analysis, factors associated with estimated glomerular filtration rate included higher mean blood pressure and glycated hemoglobin level. Longitudinal observation revealed that the decline in eGFR over 10 years was greater in TT $\left(-18.5 \pm 1.04 \mathrm{~mL} / \mathrm{min} / 1.73 \mathrm{~m}^{2}\right)$ than in CC carriers $(-16.4 \pm 0.52$ $\left.\mathrm{mL} / \mathrm{min} / 1.73 \mathrm{~m}^{2} ; \mathrm{P}<0.05\right)$.

Conclusion: The present study suggests that renal function declines faster in individuals with the TT genotype at the IGF-1 rs35767 locus than in those with the CC genotype, suggesting that the TT genotype is associated with the long-term chronological decline in renal function.

\section{Background}

Insulin-like growth factor-1 (IGF-1), also known as somatomedin C, is an endocrine hormone produced in the liver. IGF-1 exerts insulin-like action, affecting human growth and cell proliferation. The secretion of IGF-1 is stimulated by growth hormone, insulin, and dietary protein intake and is modulated by age, sex, ethnicity, and genetic predisposition. IGF-1 not only acts on glucose and protein metabolism but also has an influence on blood pressure (BP) and renal function. Circulating IGF-1 normally reaches peak levels during puberty, gradually declining with advancing age [1]. The role of IGF-1 in BP regulation is complex. Studies have shown that IGF-1 levels are higher in patients with hypertension than in those without [2-6]. In patients with excessively high IGF-1 levels, as in acromegaly, a positive relationship has been observed between IGF-1 level and BP [7]. However, other studies report that the relationship between BP and IGF-1 level is neutral [8,9] or even inverse [10-18]. In an animal model, IGF-1 was reported to decrease systemic $\mathrm{BP}$ and increase blood flow in selective vascular beds [19]. In addition, IGF-1 directly stimulates nitric oxide (NO) production in endothelial cells [20]. Interestingly, in spontaneously hypertensive rats, IGF-1induced vasorelaxant effects are impaired [21]. In contrast, GH and IGF-1 act on the renal tubule to 
promote the retention of sodium and water in the body, contributing to sodium-dependent hypertension [22]. Together, these observations suggest that IGF-1 helps in either increasing or lowering BP, depending on the conditions.

Genome-wide association studies show that the total number of hypertension-related gene loci is well over 500, even if it is limited to common mutations among determined genes. Although their influence on $\mathrm{BP}$ in the general population is only about $1 \mathrm{mmHg}$ [23], some gene mutations are reported to have a relatively large effect on BP. Most of these mutations affect water/electrolyte channels and transporters at the tubular level $[24,25]$.

Clinical evidence suggests that the T/C polymorphism rs35767 near the promoter region of the IGF-1 gene is associated with plasma IGF-1 levels. IGF-1 levels are higher in T carriers than in CC carriers. Interestingly, another study suggests that IGF-1 plays a role in the pathogenesis of atherosclerosis [26]. In addition, single-nucleotide polymorphism analysis of IGF-1 showed that rs35767 is associated with hypertension in Europeans [5]. A study of the relationship between IGF-1 polymorphism rs35767 and serum uric acid (UA) levels showed that non-Asian CC carriers have elevated UA levels [27]. Despite this preliminary evidence that IGF-1 plays a role in BP regulation, studies investigating the role of IGF-1 in renal function are limited.

This study investigates whether the IGF-1 gene polymorphism rs35767 is associated with metabolic syndrome indicators, including BP and glycated hemoglobin (HbA1c). Of particular focus is the relationship between IGF-1 genotype and long-term changes in renal function.

\section{Methods}

\section{Aim, Design, and Setting}

This study aimed to investigate whether the IGF-1 gene polymorphism rs35767 is associated with metabolic syndrome indicators, including BP and glycated hemoglobin ( $\mathrm{HbA1c}$ ). This is a retrospective, cross-sectional, longitudinal cohort study conducted in Japan.

\section{Characteristics of Participants}

The original candidate group included 3250 native Japanese living in the vicinity of Tokyo. They attended annual medical check-ups at our health management center. After being informed of the experimental protocol, 2601 of the 3250 individuals agreed to participate in the study. Of the 2601 patients, 543 (20.8\%) were treated for medical conditions, including hypertension [ $n=283(10.8) ; F / M, 1 / 272]$, diabetes mellitus [ $n=111$ (4.3\%); F/M, 4/107], and hyperuricemia [ $=149$ (5.7\%); F/M, 0/149].

\section{Laboratory Tests}

Blood was drawn after an 8-12-h fasting. Measured biochemical parameters included serum aspartate aminotransferase (AST), alanine aminotransferase (ALT), creatinine (Cr), and UA levels, as well as lipid 
profiles of total cholesterol, high-density lipoprotein cholesterol (HDLC), low-density lipoprotein cholesterol (LDLC), triglyceride (TG), and HbA1c.

\section{Other Variables}

Body mass index $(\mathrm{BMI})$ was calculated using the following equation: $\mathrm{BMI}=$ Body weight $\times 1 /$ (body height) ${ }^{2}$. BP was measured with the patient in a sitting position during a morning visit (fasting state, time: 9-11 AM) after 5 min of rest in a supine position (to avoid the so-called "white coat hypertension") using an automatic self-measuring device equipped with a $47 \times 13-\mathrm{cm}$ cuff and $24 \times 13-\mathrm{cm}$ bladder. Mean BP (MBP) was calculated from systolic BP (SBP) and diastolic BP (DBP) using the following equation: MBP $=\mathrm{DBP}+(\mathrm{SBP}-\mathrm{DBP}) / 3$. For the Japanese individuals, renal function expressed as eGFR was calculated using the following equation: eGFR $=194 \times \mathrm{Cr}^{-1.094} \times$ age $^{-0.287}$ (for women, $\times 0.739$ ), as reported elsewhere [28]. Laboratory tests were performed using the BioMajesty auto-analyzer Series JCA-9130 (JOEL, Tokyo, Japan).

\section{DNA Analysis}

Genomic DNA was extracted from whole peripheral blood cells, and samples were stored at $-80^{\circ} \mathrm{C}$ until use. Polymorphism analysis was performed by Sanger sequencing [29]. PCR reactions were performed in a total volume of $20 \mu \mathrm{L}$ containing $50 \mathrm{ng}$ genomic DNA, TaKaRa Ex Taq DNA Polymerase supplied by Takara Bio Inc., and $10 \mu \mathrm{M}$ of each forward and reverse primers. PCR amplification was performed in a DNA thermal cycler (BIO-RAD DNA Engine Peltier Thermal Cycler). The amplification conditions were as follows: initial denaturation at $94^{\circ} \mathrm{C}$ for 5 min followed by 35 cycles of $94{ }^{\circ} \mathrm{C}$ for $30 \mathrm{~s}, 60^{\circ} \mathrm{C}$ for $30 \mathrm{~s}$, and $72{ }^{\circ} \mathrm{C}$ for $30 \mathrm{~s}$, with final extension for $5 \mathrm{~min}$ at $72{ }^{\circ} \mathrm{C}$. The amplified PCR products were visualized by $1 \%$ agarose gel electrophoresis under UV light. Primers ordered from Eurofins Genomics K.K. Tokyo, Japan, were as follows; 5'-TTGGGCACATAGTAGAGCTCAC-3' and 5'-CAAAAGCCCAGAGCAGACAT-3'.

\section{Ethical Considerations}

This study was conducted in accordance with the principles set out in the Declaration of Helsinki 1964 as modified by subsequent revisions. The study protocol was reviewed and approved by the Ethics Committee of the Jikei Institutional Review Board, Jikei University School of Medicine (approval number: 29-143 8759). This study was also approved by the participating institution's review board.

\section{Statistical Analysis}

The database and all statistical outputs were retained by the University. Access to the database was limited as deemed necessary. The authors assume full responsibility for the completeness and accuracy of the content of the manuscript. Results of the different subgroups were examined by one-way analysis of variance. The final variables were chosen on the basis of clinical importance and biological plausibility at the investigators' discretion. Multiple regression analysis was used to calculate the regression coefficient ( $\beta$ ) and standard error (SE) to estimate factors affecting BP, HbA1c, UA, and eGFR after adjusting confounders. For eGFR, both cross-sectional and longitudinal analyses were performed. 
Statistical analyses were performed using Stat Flex version 7.0 (Artec Ltd. Co., Osaka, Japan) and EZR (Version 1.33, Saitama Medical Center, Jichi Medical University, Saitama, Japan), which is a graphical user interface for R (The R Foundation for Statistical Computing, Vienna, Austria). EZR is a modified version of $\mathrm{R}$ Commander designed to add statistical functions frequently used in biostatistics. Data are presented as the mean \pm standard deviation unless otherwise indicated. P-values of $\leq 0.05$ were considered statistically significant. Because the histograms of each parameter distributed in a parametric manner, logarithmic transformation was not performed.

\section{Results}

The final cohort included 2182 males and 419 females $(n=2601 ; 16.1 \%$ female). The cohort was grouped according to IGF-1 rs35767 genotype as CC [n = 1124 (43.2\%); F/M, 203/921], TC [n = 1180 (45.4\%); F/M, 170/1010], and TT [n = 297 (11.4\%); F/M, 46/251] (Table 1).

Biochemical parameters of participants according to rs35767 genotype are shown in Table 1. The serum UA level was higher in TC carriers than in CC or TT carriers $(P<0.05)$. Because of the skewed distribution of sex between the groups, the serum UA level was compared independently for each sex. The serum UA levels did not differ among the three genotypes for males or females (data not shown). No difference was observed in any of the other parameters.

The association between IGF-1 genotype and BP (SBP, DBP, and MBP) was determined using multiple regression analysis with $\mathrm{CC}$ as the standard for comparison (Table 2). Using three models (Model 1, male only; Model 2, female only; and Model 3, both sexes), we observed no association between SBP and genotype in any of the three independent models. However, in females, DBP and MBP were associated with the TT genotype $(P<0.05)$. No association was observed between rs35767 genotype and HbA1c level, serum UA level, or eGFR in any of the three models (Table 3 ).

Cross-sectional multiple regression analysis showed that eGFR was positively associated with MBP $(\mathrm{P}<$ $0.05)$ and $\mathrm{HbA} 1 \mathrm{c}(\mathrm{P}<0.05)$ and negatively associated with serum UA level $(P<0.05)($ Table 4$)$. eGFR was not associated with the TT genotype.

The results of longitudinal analysis of factors to explain time-dependent change in eGFR $(\Delta \mathrm{eGFR})$ are shown in Table 5. In a total of 1506 participants whose renal function was monitored for 10 years, we observed a gradual decline in eGFR of approximately $1.0-1.5 \mathrm{~mL} / \mathrm{min} / 1.73 \mathrm{~m}^{2} /$ year. A significant negative correlation was observed between $\triangle$ eGFR and MBP $(P<0.05)$, and between $\triangle \mathrm{eGFR}$ and HbA1c $(P<0.05) . \triangle e G F R$ correlated positively with serum UA level $(P<0.05)$. Notably, a negative association was observed between $\triangle$ eGFR and the TT genotype $(P<0.05)$.

The decline in eGFR over 10 years according to genotype is shown in Figure 1. eGFR declined significantly faster in TT carriers $\left(18.5 \pm 1.04 \mathrm{~mL} / \mathrm{min} / 1.73 \mathrm{~m}^{2} ; \mathrm{n}=169\right)$ than in CC carriers $(16.4 \pm 0.52$ $\left.\mathrm{mL} / \mathrm{min} / 1.73 \mathrm{~m}^{2} ; \mathrm{n}=650\right)(\mathrm{P}<0.05)$. 


\section{Discussion}

The notable finding of this study is that the TT genotype of the rs35767 IGF- 1 gene polymorphism is associated with a faster decline in eGFR than the CC genotype. This finding suggests that IGF-1 is not merely a metabolic growth hormone but may also influence BP and long-term renal function.

eGFR normally declines with age by approximately $1.03 \mathrm{~mL} / \mathrm{min} / 1.73 \mathrm{~m}^{2} /$ year, even in the absence of progressive renal diseases such as moderate-to-severe hypertension, overt diabetic nephropathy, and primary glomerular disease [30]. This age-related decline in renal function is caused by changes in renal morphology resulting from arteriosclerosis and concomitant renal atrophic changes. Renal function is greatly influenced by inner and middle membrane thickening and luminal narrowing that occur with age. The resulting decrease in glomerular blood flow causes collapse of the glomerular tuft and ischemia in the glomeruli and interstitial tissue, leading to an irreversible gradual loss of renal function known as nephrosclerosis.

Despite the observed association between the TT genotype and accelerated eGFR decline, DBP and MBP in females were negatively associated with the TT genotype (Table 2). The reason for this discrepancy is unclear. The negative association between TT genotype and BP suggests that the TT genotype has either a BP-lowering or a renal-protective effect. The association of DBP and MBP with the TT genotype was observed only in women; thus, we believe that this discrepancy is probably attributable to the relatively small number of female participants (16.1\%); the benefits of lowering DBP and MBP on eGFR may have been offset by the majority of male participants.

We observed that the serum UA levels differed significantly between the three genotypes, with the highest levels observed in TC carriers and the lowest in CC carriers (Table 1). However, comparison of serum UA levels by sex revealed no difference between the three genotypes in either sex. Nevertheless, our observation is not in accordance with a previous report showing that serum UA levels are lowest in TT carriers in a non-Asian, sex-matched study [27]; TT carriers also displayed higher uricosuria levels than CC carriers. Our differing result may stem from differences in the study population, including ethnicity (nonAsians vs Asians in our study), differences in sex distribution (well-balanced sex ratio vs. small number of females in our study), and age distribution (old age vs. relatively younger age in our study).

Regarding the relationship between UA and eGFR, the cross-sectional study showed a negative correlation between serum UA level and eGFR (Table 4), whereas the longitudinal study showed a positive correlation between these parameters (Table 5). The physiological role of UA as an oxidant is supported by a number of in vitro and in vivo studies reporting that intracellular UA causes inflammation, oxidative stress, endothelial dysfunction, and activation of the renin-angiotensin-aldosterone system [31]. However, UA is also known as a powerful antioxidant in the extracellular milieu [32]. Importantly, numerous studies have shown that UA is a risk factor for the progression of hypertension and CKD. For example, Kamei et al. reported that a slight increase in serum UA level within the normal range causes a decrease in renal function [33]. Conversely, in individuals with mild-to-moderate renal disease, UA is not associated with 
elevated serum Cr level or end-stage renal disease adjusted for eGFR and proteinuria [34]. The effect of UA on renal function may not be renal-toxic unless serum UA levels are extremely high [35]. At an early stage, renal dysfunction caused by hyperuricemia is predominantly arteriosclerosis-related; with progression, a J-shaped phenomenon occurs between serum UA level and intraglomerular pressure, with a concomitant increase in renal afferent arteriolar resistance [36]. In the present study, serum UA levels were nearly within normal range (approximately $5.0-6.5 \mathrm{mg} / \mathrm{dL}$ ) (Table 1). Thus, the deleterious effect of UA on renal function was not observed here.

Previous studies have shown that serum IGF-1 level depends on genotype, with TT > TC > CC [37, 38]. Accordingly, the observed decline in renal function could result from the constantly elevated IGF-1 levels. IGF-1 given intravenously decreases systemic BP and increases blood flow in selective vascular beds in animal model [19]. In addition, IGF-1 directly stimulates NO in endothelial cells [20], leading to an increase in glomerular blood flow [39]. However, GH and IGF-1 also induce hypertension. Indeed, studies show that patients with hypertension have higher IGF-1 levels than those without [2-6]. Furthermore, in a literature review of 20 studies including 11,704 subjects, Schutte et al. found a positive relationship between IGF-1 levels and BP for high IGF-1 levels in conditions such as acromegaly [7]. Notably, impairment of the IGF-1induced vasorelaxant effects has been reported in spontaneously hypertensive rats [21]. Together, these observations indicate that IGF-1 increases BP under most circumstances but can lower BP in certain medical conditions. In the presence of excessive salt, individuals with TT genotype with elevated serum IGF-1 level might be susceptible to hypertension and CKD. We speculate that presumably elevated IGF-1 levels in TT carriers resulted in their faster decline in renal function over 10 years.

IGF-1 is a hormone that decreases with age [40]. Although the precise mechanisms are largely unknown, the age-related faster decline in eGFR in TT carriers might have been related to the age-related other factors such as salt sensitivity, BP, and NO production. While gaining insight into the mechanism underlying the faster decline in eGFR in TT carriers is important, such work is beyond the scope of this study.

Although this study is unique in its relatively large cohort (2601 individuals) and the long follow-up period on renal function (10 years), there are some limitations. First, all of the participants lived in the vicinity of Tokyo and were of Japanese ethnicity. Second, the low proportion of female participants may be problematic. Third, serum IGF-1 level was not measured. Modification of such innate problems would have increased the strength of our findings.

\section{Conclusions}

This study provides preliminary evidence that the TT genotype at rs35767 in the IGF-1 gene is associated with long-term chronological decline in renal function. Future study is needed to clarify the relationship between rs35767 and renal function.

\section{List Of Abbreviations}


ALT Alanine transaminase

AST Aspartate transaminase

BMI Body mass index

BP Blood pressure

Cr Creatinine

DBP Diastolic blood pressure

eGFR estimated glomerular filtration rate

HbA1c Glycated hemoglobin

HDLC High-density lipoprotein cholesterol

IGF-1 Insulin-like growth factor-1

LDLC Low-density lipoprotein cholesterol

MBP Mean blood pressure

SBP Systolic blood pressure

TG Triglyceride

UA Uric acid

\section{Declarations}

Ethics approval and consent to participate: The study protocol was reviewed and approved by the Ethics Committee of the Jikei Institutional Review Board, Jikei University School of Medicine (approval number: 29-143 8759). This study was also approved by the participating institution's review board.

Consent for publication: Not applicable

Availability of data and materials: The datasets used and/or analyzed in this study are available on reasonable request from the corresponding author.

Competing interests: The authors declare that they have no competing interests.

Funding: This research received no specific grant from any funding agency in the public, commercial, or not-for-profit sectors. 
Authors' contributions: $\mathrm{KH}, \mathrm{SK}, \mathrm{KI}, \mathrm{NS}$, and $\mathrm{YT}$ finalized the concept and design of the study. SK and TN collected the samples. $\mathrm{KH}$ and SK performed the statistical analysis. $\mathrm{KH}, \mathrm{SK}$, and NS analyzed and interpreted the data. $\mathrm{KH}$ and SK drafted the manuscript. $\mathrm{KI}$ and $\mathrm{YT}$ performed the critical review of the manuscript. All authors read and approved the final manuscript.

Acknowledgements: Not applicable

Authors' information: Academic qualifications: KH, M.D.; SK, M.D. and Ph.D.; KI, M.D. and Ph.D.; TN, M.D. and Ph.D.; NS, M.D. and Ph.D.; T Y, M.D. and Ph.D.

\section{References}

1. Juul A. Serum levels of insulin-like growth factor I and its binding proteins in health and disease. Growth Horm IGF Res. 2003;13:113-70.

2. Jiang $X$, Srinivasan SR, Dalferes ER Jr, Berenson GS. Plasma insulin-like growth factor 1 distribution and its relation to blood pressure in adolescents: the Bogalusa Heart Study. Am J Hypertens. 1997;10:714-9.

3. Laviades C, Gil MJ, Monreal I, González A, Díez J. Is the tissue availability of circulating insulin-like growth factor I involved in organ damage and glucose regulation in hypertension? J Hypertens. 1997;15:1159-65.

4. Laviades C, Mayor G, Diez J. Elevated circulating levels of insulin-like growth factor I in essential hypertensive patients with left ventricular hypertrophy. Arch Mal Coeur Vaiss. 1991;84:1039-41.

5. Andronico G, Mangano MT, Nardi E, Mulè G, Piazza G, Cerasola G. Insulin-like growth factor 1 and sodium-lithium counter transport in essential hypertension and in hypertensive left ventricular hypertrophy. J Hypertens. 1993;11:1097-101.

6. Diez J, Ruilope LM, Rodicio JL. Insulin response to oral glucose in essential hypertensives with increased circulating levels of insulin growth factor I. J Hypertens Suppl. 1991;9:S174-5.

7. Schutte AE, Volpe M, Tocci G, Conti E. Revisiting the relationship between blood pressure and insulinlike growth factor-1. 2014;63:1070-7.

8. Vitale G, Pivonello R, Auriemma RS, Guerra E, Milone F, Savastano S, et al. Hypertension in acromegaly and in the normal population: prevalence and determinants. Clin Endocrinol (Oxf). 2005;63:470-6.

9. Colao A, Terzolo M, Bondanelli M, Galderisi M, Vitale G, Reimondo G, et al. GH and IGF-I excess control contributes to blood pressure control: results of an observational, retrospective, multicentre study in 105 hypertensive acromegalic patients on hypertensive treatment. Clin Endocrinol (Oxf). 2008;69:613-20.

10. Schutte AE, Huisman HW, van Rooyen JM, Malan L, Malan NT, Fourie CMT, et al. A significant decline in IGF-I may predispose young Africans to subsequent cardiometabolic vulnerability. J Clin Endocrinol Metab. 2010;95:2503-7. 
11. Succurro E, Andreozzi F, Sciacqua A, Letizia Hribal ML, Perticone F, Sesti G. Reciprocal association of plasma IGF-1 and interleukin-6 levels with cardiometabolic risk factors in nondiabetic subjects. Diabetes Care. 2008;31:1886-8.

12. Colao A, Di Somma C, Cascella T, Pivonello R, Vitale G, Grasso LFS, et al. Relationships between serum IGF1 levels, blood pressure, and glucose tolerance: an observational, exploratory study in 404 subjects. Eur J Endocrinol. 2008;159:389-97.

13. Zachariah JP, Xanthakis V, Larson MG, Vita JA, Sullivan LM, Smith HM, et al. Circulating vascular growth factors and central hemodynamic load in the community. 2012;59:773-9.

14. Lemne C, Brismar K. Insulin-like growth factor binding protein-1 as a marker of the metabolic syndrome-a study in borderline hypertension. Blood Press. 1998;7:89-95.

15. Landin-Wilhelmsen K, Wilhelmsen L, Lappas G, Rosén T, Lindstedt G, Lundberg PA, et al. Serum insulin-like growth factor I in a random population sample of men and women: relation to age, sex, smoking habits, coffee consumption and physical activity, blood pressure and concentrations of plasma lipids, fibrinogen, parathyroid hormone and osteocalcin. Clin Endocrinol (Oxf). 1994;41:3517.

16. Dall'Aglio E, Salimbeni I, Rocci A, Mazzoni S, Corradi F, Cattadori E, et al. Modifications of blood pressure and IGF-I levels after weight loss in obesity. J Endocrinol Invest. 2002;25:107-9.

17. Dall'Aglio E, Maggio M, Benedetti N, Caporotundo S, Salimbeni I, Banchini A, et al. IGF-I levels in obesity: their relationship to blood pressure levels. J Endocrinol Invest. 1999;22:49-50.

18. Capoluongo E, Pitocco D, Lulli P, Minucci A, Santonocito C, Manto A, et al. Inverse correlation between serum free IGF-I and IGFBP-3 levels and blood pressure in patients affected with type 1 diabetes. Cytokine. 2006;34:303-11.

19. Hu Y, Pete G, Walsh MF, Sowers J, Dunbar JC. Central IGF-1 decreases systemic blood pressure and increases blood flow in selective vascular beds. Horm Metab Res. 1996;28:211-4.

20. Tsukahara H, Gordienko DV, Tonshoff B, Gelato MC, Goligorsky MS. Direct demonstration of insulinlike growth factor-I-induced nitric oxide production by endothelial cells. Kidney Int. 1994;45:598-604.

21. Vecchione C, Colella S, Fratta L, Gentile MT, Selvetella G, Frati G, et al. Impaired insulin-like growth factor I vasorelaxant effects in hypertension. Hypertension. 2001;37:1480-5.

22. Svensson J, Tivesten A, Sjögren K, Isaksson O, Bergström G, Mohan S, et al. Liver-derived IGF-I regulates kidney size, sodium reabsorption, and renal IGF-II expression. J Endocrinol. 2007;193:35966.

23. Warren HR, Evangelou E, Cabrera CP, Gao H, Ren M, Mifsud B, et al. Genome-wide association analysis identifies novel blood pressure loci and offers biological insights into cardiovascular risk. Nat Genet. 2017;49:403-15.

24. Ji W, Foo JN, O'Roak BJ, Zhao H, Larson MG, Simon DB, et al. Rare independent mutations in renal salt handling genes contribute to blood pressure variation. Nat Genet. 2008;40:592-9.

25. R P Lifton, A G Gharavi, D S Geller. Molecular mechanisms of human hypertension. Cell. 2001;104:545-56. 
26. Mannino GC, Greco A, De Lorenzo CD, Andreozzi F, Marini MA, Perticone F, et al. A fasting insulinraising allele at IGF1 locus is associated with circulating levels of IGF-1 and insulin sensitivity. PLoS One. 2013;8:

27. Mannino GC, Fuoco A, Marini MA, Spiga R, Di Fatta C, Mancuso E, et al. The polymorphism rs35767 at IGF1 locus is associated with serum urate levels. Sci Rep. 2018;8:

28. Matsuo S, Imai E, Horio M, Yasuda Y, Tomita K, Nitta K, et al. Revised equations for estimated GFR from serum creatinine in Japan. Am J Kidney Dis. 2009;53:982-92.

29. Sanger F, Coulson AR. A rapid method for determining sequences in DNA by primed synthesis with DNA polymerase. J Mol Biol. 1975;94:441-8.

30. Eriksen BO, Ingebretsen OC. The progression of chronic kidney disease: A 10-yearpopulation-based study of the effects of gender and age. Kidney Int. 2006;69:375-82.

31. Srivastava A, Kaze AD, McMullan CJ, Isakova T, Waikar SS. Uric acid and the risks of kidney failure and death in individuals with CKD. Am J Kidney Dis. 2018;71:362-70.

32. Schwarzschild MA, Ascherio A, Beal MF, Cudkowicz ME, Curhan GC, Hare JM, et al. Parkinson Study Group S-PDI. Inosine to increase serum and cerebrospinal fluid urate in Parkinson disease: a randomized clinical trial. JAMA Neurol. 2014; 71:

33. Kamei K, Konta T, Hirayama A, Suzuki K, Ichikawa K, Fujimoto S, et al. A slight increase within the normal range of serum uric acid and the decline in renal function: associations in a communitybased population. Nephrol Dial Transplant. 2014;29:2286-92.

34. Sturm G, Kollerits B, Neyer U, Ritz E, Kronenberg F, Group MS. Uric acid as a risk factor for progression of non-diabetic chronic kidney disease? The Mild to Moderate Kidney Disease (MMKD) Study. Exp Gerontol. 2008; 43:347-52.

35. Bellomo G, Venanz Si, Verdura C, Saronio P, Esposito A, Timio M. Association of uric acid with change in kidney function in healthy normotensive individuals. Am J Kidney Dis. 2010;56:264-72.

36. Uedono H, Tsuda A, Ishimura E, Nakatani S, Kurajoh M, Mori K, et al. U-shaped relationship between serum uric acid levels and intrarenal hemodynamic parameters in healthy subjects. Am J Physiol Renal Physiol. 2017;312:F992-7.

37. Sesti G, Mannino GC, Andreozzi F, Greco A, Perticone M, Sciacqua A, et al. A polymorphism at IGF1 locus is associated with carotid intima media thickness and endothelium-dependent vasodilatation. Atherosclerosis. 2014;232:25-30.

38. Li Y, Zhou X, Liu R, Cao Y, Wang L, Chaolnt X, et al. Relationship of SNP rs35767 in IGF-1 promoter region with susceptibility to colorectal cancer. J Clin Exp Pathol. 2018;11:5110-6.

39. Haylor J, Singh I, el Nahas AM. Nitric oxide synthesis inhibitor prevents vasodilation by insulin-like growth factor I. Kidney Int. 1991;39:333-5.

40. Sonntag WE, Deak F, Ashpole N, Toth P, Csiszar A, Freeman W, Ungvari Z. Insulin-like growth factor-1 in CNS and cerebrovascular aging. Front Aging Neurosci. 2013;5:27. 


\section{Tables}

Table 1. Characteristics of participants according to the SNP rs35767 genotype*

\begin{tabular}{|c|c|c|c|c|}
\hline & \multicolumn{4}{|l|}{ Genotype } \\
\hline & $\mathrm{CC}$ & $\mathrm{TC}$ & TT & $P$ \\
\hline Sex (Female/Male) & $203 / 921$ & $170 / 1,010$ & $46 / 251$ & 0.06 \\
\hline Age (years) & $40.8 \pm 9.3$ & $41.4 \pm 9.3$ & $40.9 \pm 9.5$ & 0.42 \\
\hline BMI $\left(\mathrm{kg} / \mathrm{m}^{2}\right)$ & $23.2 \pm 3.9$ & $23.3 \pm 3.83$ & $22.9 \pm 3.4$ & 0.18 \\
\hline SBP $(m m H g)$ & $118.5 \pm 13.8$ & $119.7 \pm 14.9$ & $118.3 \pm 14.2$ & 0.08 \\
\hline $\mathrm{DBP}(\mathrm{mmHg})$ & $78.0 \pm 10.0$ & $78.6 \pm 10.3$ & $77.6 \pm 10.5$ & 0.17 \\
\hline MBP $(\mathrm{mmHg})$ & $91.5 \pm 10.6$ & $92.3 \pm 11.2$ & $91.2 \pm 11.2$ & 0.1 \\
\hline AST (IU/L) & $23.3 \pm 12.4$ & $23.7 \pm 11.4$ & $23.0 \pm 9.1$ & 0.48 \\
\hline ALT (IU/L) & $26.3 \pm 22.0$ & $26.7 \pm 19.5$ & $25.4 \pm 18.7$ & 0.63 \\
\hline $\mathrm{Cr}(\mathrm{mg} / \mathrm{dL})$ & $0.81 \pm 0.14$ & $0.83 \pm 0.26$ & $0.83 \pm 0.31$ & 0.07 \\
\hline eGFR $\left(\mathrm{mL} / \mathrm{min} / 1.73 \mathrm{~m}^{2}\right)$ & $82.7 \pm 13.9$ & $82.0 \pm 14.3$ & $82.2 \pm 13.9$ & 0.48 \\
\hline $\mathrm{UA}(\mathrm{mg} / \mathrm{dL})$ & $5.8 \pm 1.4$ & $6.0 \pm 1.4$ & $5.9 \pm 1.2$ & $<0.05$ \\
\hline $\mathrm{TC}(\mathrm{mg} / \mathrm{dL})$ & $200.6 \pm 33.4$ & $200.1 \pm 33.2$ & $197.1 \pm 32.1$ & 0.26 \\
\hline HDLC (mg/dL) & $64.0 \pm 16.0$ & $64.4 \pm 16.3$ & $63.8 \pm 15.1$ & 0.81 \\
\hline LDLC (mg/dL) & $122.6 \pm 31.9$ & $121.5 \pm 31.0$ & $119.7 \pm 30.4$ & 0.34 \\
\hline TG (mg/dL) & $106.2 \pm 80.8$ & $109.5 \pm 83.3$ & $101.5 \pm 82.6$ & 0.29 \\
\hline HbA1c (\%) & $5.37 \pm 0.65$ & $5.35 \pm 0.54$ & $5.29 \pm 0.41$ & 0.09 \\
\hline
\end{tabular}

$*_{n}=2601$

Data are presented as the mean \pm standard deviation.

Abbreviations: SNP, single-nucleotide polymorphism; IGF-1, insulin-like growth factor-1; BMI, body mass index; SBP, systolic blood pressure; DBP, diastolic blood pressure; MBP, mean blood pressure; AST, aspartate transaminase; ALT, alanine transaminase; $\mathrm{Cr}$, creatinine; eGFR, estimated glomerular filtration rate; UA, uric acid; TC, total cholesterol; HDLC; high-density lipoprotein cholesterol; LDLC; low-density lipoprotein cholesterol; TG, triglyceride; HbA1c, glycated hemoglobin 
Table 2. BP according to rs35767 genotype

\begin{tabular}{|c|c|c|c|c|c|c|c|c|c|c|c|c|c|c|c|c|c|c|}
\hline \multirow{3}{*}{ Model } & \multicolumn{6}{|c|}{ SBP } & \multicolumn{6}{|c|}{ DBP } & \multicolumn{6}{|c|}{ MBP } \\
\hline & \multicolumn{2}{|c|}{$1(\mathrm{M})$} & \multicolumn{2}{|c|}{$2(\mathrm{~F})$} & \multicolumn{2}{|c|}{ 3(All) } & \multicolumn{2}{|c|}{$1(\mathrm{M})$} & \multicolumn{2}{|c|}{$2(\mathrm{~F})$} & \multicolumn{2}{|c|}{ 3(All) } & \multicolumn{2}{|c|}{ 1(M) } & \multicolumn{2}{|c|}{$2(\mathrm{~F})$} & \multicolumn{2}{|c|}{ 3(All) } \\
\hline & $\begin{array}{c}\beta \\
(\mathrm{SE})\end{array}$ & $\mathrm{p}$ & $\begin{array}{c}\beta \\
(\mathrm{SE})\end{array}$ & $\mathrm{p}$ & $\begin{array}{c}\beta \\
(\mathrm{SE})\end{array}$ & $\mathrm{p}$ & $\begin{array}{c}\beta \\
(\mathrm{SE})\end{array}$ & $\mathrm{p}$ & $\begin{array}{c}\beta \\
(\mathrm{SE})\end{array}$ & $\mathrm{p}$ & $\begin{array}{c}\beta \\
(\mathrm{SE})\end{array}$ & $\mathrm{p}$ & $\begin{array}{c}\beta \\
(\mathrm{SE})\end{array}$ & $\mathrm{p}$ & $\begin{array}{c}\beta \\
(\mathrm{SE})\end{array}$ & $\mathrm{p}$ & $\begin{array}{c}\beta \\
(\mathrm{SE})\end{array}$ & $\mathrm{p}$ \\
\hline $\mathrm{CC}$ & Ref & & Ref & & Ref & & Ref & & Ref & & Ref & & Ref & & Ref & & Ref & \\
\hline TC & $\begin{array}{c}-0.17 \\
(-0.60)\end{array}$ & 0.77 & $\begin{array}{c}-0.85 \\
(-1.16)\end{array}$ & 0.47 & $\begin{array}{c}-0.35 \\
(-0.54)\end{array}$ & 0.51 & $\begin{array}{c}-0.27 \\
(-0.43)\end{array}$ & 0.52 & $\begin{array}{c}-0.64 \\
(-0.80)\end{array}$ & 0.42 & $\begin{array}{c}-0.35 \\
(-0.38)\end{array}$ & 0.36 & $\begin{array}{c}-0.24 \\
(-0.45)\end{array}$ & 0.6 & $\begin{array}{c}-0.71 \\
(-0.86)\end{array}$ & 0.41 & $\begin{array}{c}-0.35 \\
(-0.40)\end{array}$ & 0.39 \\
\hline TT & $\begin{array}{c}-0.42 \\
(-0.92)\end{array}$ & 0.65 & $\begin{array}{c}-2.53 \\
(-1.82)\end{array}$ & 0.17 & $\begin{array}{c}-0.75 \\
(-0.83)\end{array}$ & 0.37 & $\begin{array}{c}0.02 \\
(-0.04)\end{array}$ & 0.97 & $\begin{array}{c}-2.81 \\
(-1.25)\end{array}$ & $<0.05$ & $\begin{array}{c}-0.48 \\
(-0.599\end{array}$ & 0.41 & $\begin{array}{c}-0.12 \\
(-0.70)\end{array}$ & 0.86 & $\begin{array}{c}-2.71 \\
(-1.35)\end{array}$ & $<0.05$ & $\begin{array}{l}-0.57 \\
(-0.62)\end{array}$ & 0.36 \\
\hline
\end{tabular}

Model 1, males only (M); Model 2, females only (F); Model 3, males and females (All); all models adjusted for age, BMI, eGFR, UA, LDLC, HbA1c

$\mathrm{N}=2318(\mathrm{~F} / \mathrm{M}, 408 / 1910)$ patients without treatment for hypertension

SBP, systolic blood pressure; DBP, diastolic blood pressure; MBP, mean blood pressure; BMI, body mass index; eGFR, estimated glomerular filtration rate; UA, uric acid; LDLC, low-density lipoprotein cholesterol; $\mathrm{HbA1c}$, glycated hemoglobin; $\beta$, regression coefficients; ref, reference; SE, standard error

Table 3. Association of rs 35767 genotype with HbA1c, UA, and eGFR according to sex

\begin{tabular}{|c|c|c|c|c|c|c|c|c|c|c|c|c|c|c|c|c|c|c|}
\hline \multirow{3}{*}{ Model } & \multicolumn{6}{|c|}{ HbAlc } & \multicolumn{6}{|c|}{ UA } & \multicolumn{6}{|c|}{ eGFR } \\
\hline & \multicolumn{2}{|c|}{$1(\mathrm{M})$} & \multicolumn{2}{|c|}{$2(F)$} & \multicolumn{2}{|c|}{ 3(All) } & \multicolumn{2}{|c|}{$1(\mathrm{M})$} & \multicolumn{2}{|c|}{$2(\mathrm{~F})$} & \multicolumn{2}{|c|}{ 3(All) } & \multicolumn{2}{|c|}{$1(\mathrm{M})$} & \multicolumn{2}{|c|}{$2(F)$} & \multicolumn{2}{|c|}{ 3(All) } \\
\hline & $\begin{array}{c}\beta \\
(\mathrm{SE})\end{array}$ & $\mathrm{p}$ & $\begin{array}{c}\beta \\
(\mathrm{SE})\end{array}$ & $\mathrm{p}$ & $\begin{array}{c}\beta \\
(\mathrm{SE})\end{array}$ & $\mathrm{p}$ & $\begin{array}{c}\beta \\
(\mathrm{SE})\end{array}$ & $\mathrm{p}$ & $\begin{array}{c}\beta \\
(\mathrm{SE})\end{array}$ & $\mathrm{p}$ & $\begin{array}{c}\beta \\
(\mathrm{SE})\end{array}$ & $\mathrm{p}$ & $\begin{array}{c}\beta \\
(\mathrm{SE})\end{array}$ & $\mathrm{p}$ & $\begin{array}{c}\beta \\
(\mathrm{SE})\end{array}$ & $\mathrm{p}$ & $\begin{array}{c}\beta \\
(\mathrm{SE})\end{array}$ & $\mathrm{p}$ \\
\hline $\mathrm{CC}$ & Ref & & Ref & & Ref & & Ref & & Ref & & Ref & & Ref & & Ref & & Ref & \\
\hline $\mathrm{TC}$ & $\begin{array}{l}-0.01 \\
(0.02)\end{array}$ & 0.44 & $\begin{array}{l}-0.05 \\
(0.03)\end{array}$ & 0.06 & $\begin{array}{l}-0.02 \\
(0.01)\end{array}$ & 0.20 & $\begin{array}{c}0.09 \\
(0.05)\end{array}$ & 0.11 & $\begin{array}{c}0.10 \\
(0.10)\end{array}$ & 0.30 & $\begin{array}{c}0.09 \\
(0.05)\end{array}$ & 0.05 & $\begin{array}{l}-0.09 \\
(0.53)\end{array}$ & 0.86 & $\begin{array}{c}0.78 \\
(1.39)\end{array}$ & 0.58 & $\begin{array}{c}0.06 \\
(0.50)\end{array}$ & 0.90 \\
\hline TT & $\begin{array}{l}-0.03 \\
(0.03)\end{array}$ & 0.25 & $\begin{array}{l}-0.04 \\
(0.04)\end{array}$ & 0.30 & $\begin{array}{l}-0.03 \\
(0.02)\end{array}$ & 0.17 & $\begin{array}{c}0.06 \\
(0.08)\end{array}$ & 0.45 & $\begin{array}{c}0.25 \\
(0.15)\end{array}$ & 0.09 & $\begin{array}{c}0.10 \\
(0.07)\end{array}$ & 0.19 & $\begin{array}{c}0.01 \\
(0.83)\end{array}$ & 1.00 & $\begin{array}{l}-0.96 \\
(2.18)\end{array}$ & 0.66 & $\begin{array}{l}-0.08 \\
(0.78)\end{array}$ & 0.92 \\
\hline
\end{tabular}


Model 1, males only (M); Model 2, females only (F); Model 3, males and females (All); all models adjusted for age, BMI, MBP, eGFR, UA, LDLC, HbA1c

$N=2452$ patients without UA treatment; $F / M=419 / 2033$

Abbreviations: HbA1c, glycated hemoglobin; UA, uric acid; eGFR, estimated glomerular filtration rate; BMI, body mass index; LDLC, low-density lipoprotein cholesterol; MBP, mean blood pressure; $\beta$, regression coefficients; ref, reference; SE, standard error

Table 4. Cross-sectional analysis of factors to explain eGFR*

\begin{tabular}{|llll|}
\hline Objective variable & eGFR & & \\
\hline & $\beta(S E)$ & $t$ & $p$ \\
\hline BMI $\left(\mathrm{kg} / \mathrm{m}^{2}\right)$ & $0.12(0.14)$ & 0.86 & 0.39 \\
\hline MBP $(\mathrm{mmHg})$ & $0.07(0.04)$ & 1.98 & $<0.05$ \\
\hline LDLC $(\mathrm{mg} / \mathrm{dL})$ & $-0.02(0.02)$ & -1.57 & 0.12 \\
\hline UA $(\mathrm{mg} / \mathrm{dL})$ & $-2.26(0.36)$ & -7.39 & $<0.05$ \\
\hline HbA1c $(\%)$ & $2.92(0.72)$ & 4.08 & $<0.05$ \\
\hline rs35767 polymorphism & & & \\
\hline CC & Ref & & \\
\hline TC & $0.34(0.85)$ & 0.4 & 0.69 \\
\hline TT & $1.96(1.34)$ & 1.46 & 0.15 \\
\hline
\end{tabular}

*N $=1506$ individuals who were followed up for 10 years $(F / M=206 / 1300)$

Model includes sex, age, BMI, MBP, UA, LDLC, HbA1c, and rs35767genotype.

Table 5. Longitudinal analysis of factors to explain the decline in eGFR* 


\begin{tabular}{|llll|}
\hline Objective variable & \multicolumn{4}{l}{$\Delta$ eGFR in 10 years } \\
\hline & B $(\mathrm{SE})$ & $\mathrm{t}$ & $\mathrm{p}$ \\
\hline $\mathrm{BMI}\left(\mathrm{kg} / \mathrm{m}^{2}\right)$ & $-0.01(0.11)$ & -0.08 & 0.94 \\
\hline MBP $(\mathrm{mmHg})$ & $-0.06(0.03)$ & -1.97 & $<0.05$ \\
\hline LDLC $(\mathrm{mg} / \mathrm{dL})$ & $0.01(0.93)$ & 0.72 & 0.47 \\
\hline UA $(\mathrm{mg} / \mathrm{dL})$ & $1.17(0.28)$ & 4.12 & $<0.05$ \\
\hline HbA1c $(\%)$ & $-2.30(0.57)$ & -4.07 & $<0.05$ \\
\hline rs35767 polymorphism & & & \\
\hline CC & Ref & & \\
\hline TC & $-0.19(0.67)$ & -0.28 & 0.78 \\
\hline TT & $-2.42(1.06)$ & -2.28 & $<0.05$ \\
\hline
\end{tabular}

${ }^{*} N=1506$ individuals who were followed up for 10 years $(F / M=206 / 1300)$

Model includes sex, age, BMI, MBP, UA, LDLC, HbA1c, and rs35767 genotype.

\section{Figures}


Decline in eGFR in 10 years

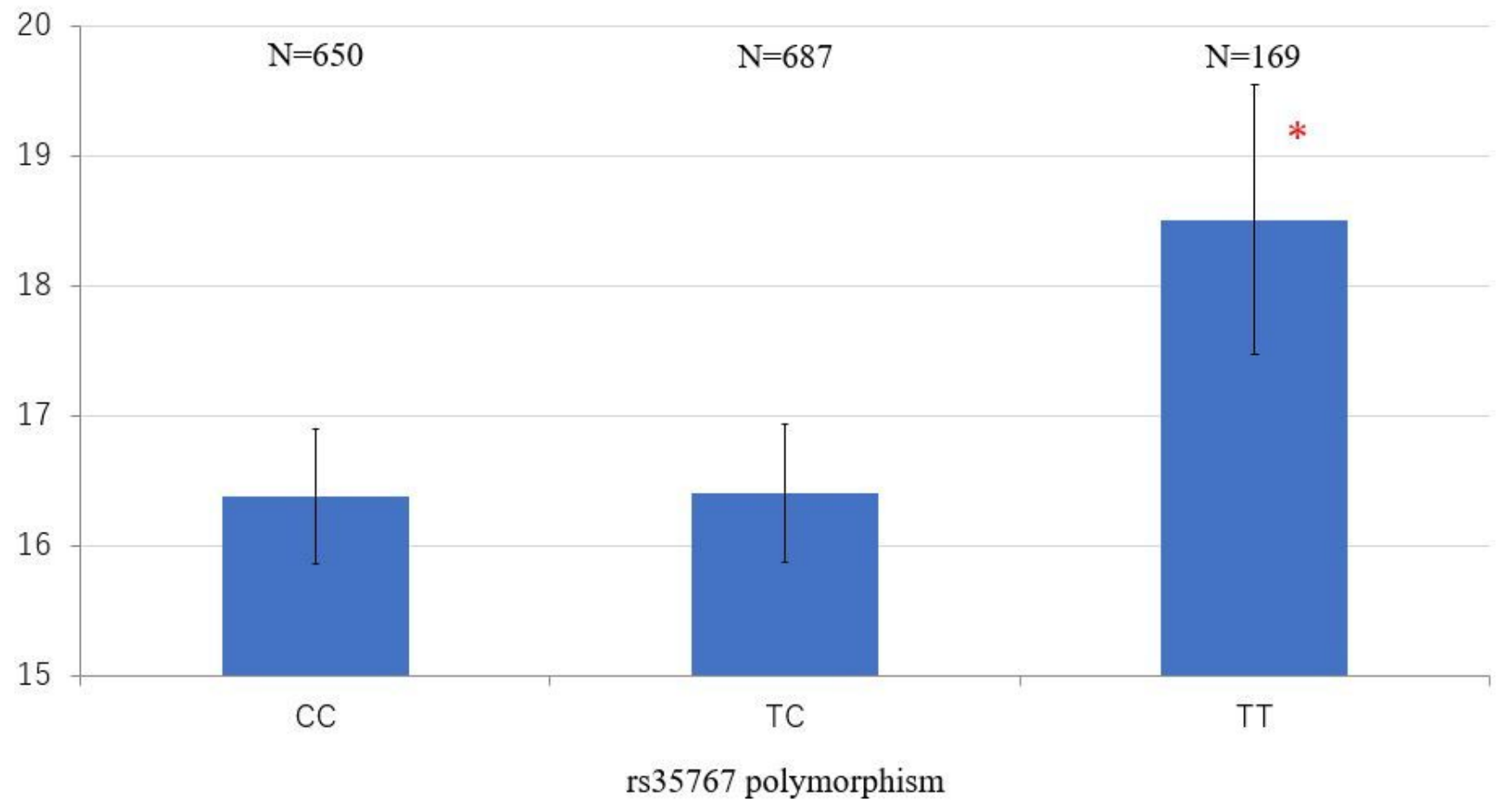

\section{Figure 1}

Decline in eGFR according to three IGF-1 rs35767 genotypes. N= 1506 (F/M = 206/1300) individuals who were followed up for 10 years * $P<0.01$, multiple regression analysis. Bars represent standard error of the mean.

\section{Supplementary Files}

This is a list of supplementary files associated with this preprint. Click to download.

- Additionalfile2.pptx

- Additionalfile1.pptx 